\title{
Retinoids Induce Growth Inhibition and Apoptosis in Mast Cell Tumor Cell Lines
}

\author{
Emi OHASHI ${ }^{1)}$, Nozomi MIYAJIMA ${ }^{1)}$, Takayuki NAKAGAWA ${ }^{1)}$, Tomoko TAKAHASHI ${ }^{2)}$, Hiroyuki KAGECHIKA ${ }^{3)}$, \\ Manabu MOCHIZUKI ${ }^{1)}$, Ryohei NISHIMURA ${ }^{1)}$ and Nobuo SASAKI ${ }^{1) *}$ \\ ${ }^{1)}$ Laboratory of Veterinary Surgery, Graduate School of Agricultural and Life Sciences, The University of Tokyo, 1-1-1 Yayoi, Bunkyo-ku, \\ Tokyo 113-8657, 2) Department of Veterinary Medicine, College of Bioresource Sciences, Nihon University, 1866 Kameino, Fujisawa, \\ Kanagawa 252-8510 and ${ }^{3}$ School of Biomedical Science, Tokyo Medical and Dental University, 2-3-10 Kanda-Surugadai, Chiyoda-ku, \\ Tokyo 101-0062, Japan
}

(Received 29 August 2005/Accepted 12 April 2006)

ABSTRACT. Retinoids are well recognized as promising antitumor agents in humans. However, there have only been a few reports about the effect of retinoids in canine cancers. To investigate the antitumor effect of retinoids on mast cell tumors (MCT), inhibitory effect on cell growth and induction of apoptosis were examined in vitro. Although sensitivity of these cells differed among the cells, the growth of three MCT cell lines (CoMS, CM-MC and VI-MC) were inhibited dose dependently when they were treated with retinoids. FACS analysis of PI-stained nuclei revealed an apoptotic fraction in CM-MC cells about 30\% when treated with retinoids, while those of control cells were less than 5\%. Caspase-3 activation was observed after retinoid treatment in CM-MC cells. This was confirmed by inhibiting the retinoid-induced apoptosis using the pan-caspase inhibitor, ZVAD-FMK. Both retinoid receptors, RARs and RXRs, were detected by immunoprecipitation followed by western blot analysis in all the three MCT cells. These data suggests that retinoids inhibit the growth of MCTs partly through apoptosis, and this growth inhibition by retinoids may be mediated by RARs and RXRs. We conclude that retinoid may be a potential adjunctive chemotherapeutic agent for the treatment of canine MCT. KEY WORDS: canine, mast cell tumor, retinoid.

Mast cell tumors (MCTs) represent the most common cutaneous tumor in the dog, accounting for between 16 to $21 \%$ of all cutaneous tumors [28]. Histologic grading, determined by the morphologic characteristics of the neoplastic cells, has been established as the most consistent prognostic factor highly predictive of biological behavior and clinical outcome [19]. The majority of dogs that suffer undifferentiated MCTs carry a poor prognosis [19]. Surgical excision and radiation therapy have been the most successful treatment modality for MCTs described to date, and the use of adjuvant chemotherapy is indicated after the excision of grade 3, metastatic and nonresectable MCTs [23]. However, chemotherapy for canine MCT has been unrewarding, and long-term responses have not been demonstrated in well-controlled clinical trials. Therefore, there is a need for chemotherapy to be improved in order to obtain a better prognosis in undifferentiated MCTs.

Retinoids are active metabolites of vitamin A and modulate various biological functions such as cell differentiation, proliferation and embryonic development in vertebrates [11]. It has been well established that retinoidal activities result mainly from the transcriptional regulation of specific gene programs. Retinoids bind to and activate two classes of receptors, retinoic acid receptors (RARs) and retinoid X receptors (RXRs), both of which belong to the steroid/thyroid hormone receptor superfamily $[4,13,16,20]$. Preclinical and clinical studies suggest that retinoids induce the

\footnotetext{
* Correspondence to: Sasaki, N., Laboratory of Veterinary Surgery, Graduate School of Agricultural and Life Sciences, The University of Tokyo, 1-1-1 Yayoi, Bunkyo-ku, Tokyo 1138657, Japan.
}

growth inhibition of various kinds of cancers in human through differentiation and apoptosis. All-trans retinoic acid (ATRA) and 9-cis retinoic acid (9cRA) are natural retinoids, and Am80 is a synthetic retinoid. ATRA activates only RARs, while 9cRA activates both RARs and RXRs [4, $13,16,20]$. Am80 can only bind to RAR alpha and beta, though their binding affinities are more potent than ATRA [27].

The potential interaction between retinoids and cancer therapy has been recognized for decades, acute promyelocytic leukemia (APL) being the most notable example. APL can be effectively eradicated by retinoids, and therefore forms the prototype for retinoid-based therapies [22]. In contrast, retinoids have been used mainly in dermatology as a differentiating agent for sebaceous adenitis in dogs [30]. There have only been few studies that have discussed the effect of retinoids on canine cancers $[17,29]$. In our laboratory, we have previously shown the effect of retinoids in canine osteosarcoma and melanoma cells $[6,7,18]$. Osteosarcoma cells showed significant growth inhibition when treated with retinoids, although significant growth inhibition was only seen when the cells were treated with the highest dose, $10^{-5} \mathrm{M}[6,7]$. No effects on the growth rate or differentiation of melanoma cell lines were observed [18].

It has recently been reported that treatment with ATRA results in the decrease of mast cells when ATRA is added to the human mast cell progenitor cells [12]. The purpose of this study was to investigate the antitumor effect of retinoids in MCT cell lines using three kinds of natural and synthetic retinoids, in order to further evaluate the potential efficacy of retinoids on canine cancers. 


\section{MATERIALS AND METHODS}

Cell culture: Three canine MCT cell lines (CoMS, CM$\mathrm{MC}$ and VI-MC) were used in this study [9, 21]. CoMS and VI-MC cells were cultured in RPMI-1640 medium (Nissui Pharmaceutical Co., Tokyo, Japan) supplemented with $10 \%$ heat-inactivated $\left(56^{\circ} \mathrm{C}, 30 \mathrm{~min}\right)$ fetal bovine serum (FBS), 2 $\mathrm{mM}$ L-glutamine, $50 \mathrm{mg} / \mathrm{L}$ gentamycin sulfate and $1.5 \mathrm{mg} /$ $\mathrm{L}$ amphotericin B. CM-MC cells were cultured in RPMI1640 medium supplemented with $10 \%$ heat-inactivated FBS, $2 \mathrm{mM}$ L-glutamine, $10 \mathrm{U} / \mathrm{m} l$ penicillin $\mathrm{G}, 10 \mu \mathrm{g} / \mathrm{m} l$ streptomycin and $50 \mathrm{mM} 2$-mercaptoethanol. The cells were cultured at $37^{\circ} \mathrm{C}$ in a humidified atmosphere with $5 \%$ $\mathrm{CO}_{2}$.

Reagents: ATRA and 9cRA were purchased from Sigma (St Louis, MO, U.S.A.). Am80 was kindly provided from Dr. Hiroyuki Kagechika. Retinoids were dissolved in 100\% ethanol at a concentration of $10^{-2} \mathrm{M}$ and stored in the dark at $-20^{\circ} \mathrm{C}$ under nitrogen. Stock solutions were diluted to the final concentration of $1 \times 10^{-5}-1 \times 10^{-10} \mathrm{M}$ with culture medium immediately before use. The same amount of ethanol [(less than $0.1 \%(\mathrm{vol} / \mathrm{vol})$ ] was added to the control medium. A pan-caspase inhibitor, ZVAD-FMK, was obtained from Takara Bio Inc (Shiga, Japan).

Antibodies: To detect RARs and RXRs, rabbit polyclonal antibodies for RARs and RXRs (Santa Cruz Biotechnology, Inc, Santa Cruz, CA, U.S.A.) were used in this study. For detection of caspase-3, polyclonal antibodies for pro- and active caspase-3 antibodies were obtained from Cell Signaling Technology, Inc (Beverly, MA, U.S.A.). A horse radish peroxidase (HRP) conjugated anti-rabbit antibody (Bethyl, Inc, Montgomery, TX, U.S.A.) was used as a secondary antibody in both studies.

Assays for inhibition of cell growth: The inhibitory effect of retinoids on cell growth was evaluated using the Cell Counting Kit (Dojindo Co., Osaka, Japan). The cells were plated in 96-well plates in quadruplicate, and treated with or without $1 \times 10^{-5}-1 \times 10^{-10} \mathrm{M}$ of retinoids for three days. Relative viable cells were obtained according to the manufacturer's protocol. The percentage of viable cell numbers of the treated groups was compared to that of the control $(100 \%)$.

Measurement of cell cycle distribution and sub G1 fraction: Cells were treated with $1 \times 10^{-5} \mathrm{M}$ ATRA for three days, fixed with $70 \%$ ethanol and incubated with RNase and propidium iodide (PI). Then, the cells were analyzed on a FACS Calibur (Becton Dickinson, Le Pont de Claix, France) using Cell Quest software for cell cycle distribution (sub G1, G1, S and G2). For treatment with the combination of ATRA and ZVAD-FMK, cells were treated with $1 \times 10^{-5}$ $M$ ATRA and/or $5 \times 10^{-5} \mathrm{M}$ ZVAD-FMK for four days. On the third day of incubation, the half of the spend medium was replaced with fresh control medium or medium containing ATRA and/or ZVAD-FMK.

Detection of the expression and activation of caspases: Total cell extracts from CM-MC with/without $1 \times 10^{-5} \mathrm{M}$ ATRA were prepared using Chaps cell extract buffer (Cell
Signaling Technology, Inc) according to the manufacturer's protocol. Twenty $\mathrm{mg}$ protein per sample was loaded onto a $15 \%$ sodium dodecyl sulfate (SDS) acrylamide gel and fractionated by electrophoresis, then electrotransferred onto a polyvinylidene difluoride (PVDF) membrane (Pall Co, NY, U.S.A.) and immunoblotting was performed according to the manufacturer's protocol. Bands were visualized with a chemiluminescence-based procedure using the PhototopeHRP Western Blot Detection kit (Cell Signaling Technology, Inc).

Detection of RARs and RXRs: Nuclear extracts were prepared as described elsewhere $[1,5]$. Protein concentrations were determined by protein assay kit (Bio-Rad Laboratories, Inc, Tokyo, Japan) based on the method of Bradford [2]. Immunoprecipitation of nuclear extracts ( $3 \mathrm{mg}$ protein) was performed using the immunoprecipitation kit, according to the manufacturer's protocol (Roche Diagnostics, Basel, Switzerland). Immunoprecipitates were loaded onto $10 \%$ SDS acrylamide gel, fractionated by electrophoresis and electrotransferred onto a PVDF membrane (Bio-Rad Laboratories, Inc). Primary antibodies were incubated with membranes for $1 \mathrm{hr}$ at room temperature in Tris-Buffered Saline (TBS), then secondary antibodies were incubated with membranes for $1 \mathrm{hr}$. Blot was detected by diaminobenzidine solution (Sigma).

The specificity of the reaction was checked using samples immunoprecipited with control anti-rabbit IgG, and subsequently immunostained with the specific rabbit polyclonal antibodies.

Statistical analysis: All experiments were carried out at least 3 times, and were shown to be reproducible. The difference in cell growth within each retinoid-treated group was analyzed using one-factor ANOVA for repeated measure, followed by the Sheffe's F test. For comparison of the changes in cell viability between each retinoid-treated group, one-factor ANOVA followed by the Scheffe's F test was used. Values were expressed as means $\pm \mathrm{SD}$, and $\mathrm{P}<0.05$ was considered significant.

\section{RESULTS}

Assays for inhibition of cell growth: Cell viability was measured after three days of exposure to ATRA, 9cRA and Am80 at the dose of $1 \times 10^{-5}-1 \times 10^{-10} \mathrm{M}$ (Fig. 1). Doses that caused 50\% inhibition (IC50 values) are shown in Table 1. Although sensitivity to retinoids varied between the cell lines, dose-dependent growth inhibition was observed in all the three cell lines. CM-MC cells showed the highest sensitivity among the cells, with the IC50 being $9.7 \times 10^{-8} \mathrm{M}$ and $2.2 \times 10^{-9} \mathrm{M}$ in ATRA and 9cRA, respectively. IC50 of ATRA in VI-MC cells and Am80 in all the three cell lines could not be calculated, because the growth inhibition rate was less than $50 \%$ even at the highest dose $\left(1 \times 10^{-5} \mathrm{M}\right)$.

Measurement of cell cycle distribution and sub G1 fraction: Flow cytometry analysis of PI-stained nuclei was performed to examine the cell cycle distribution and cell cycle arrest imposed by ATRA treatment. The nuclei in apoptotic 

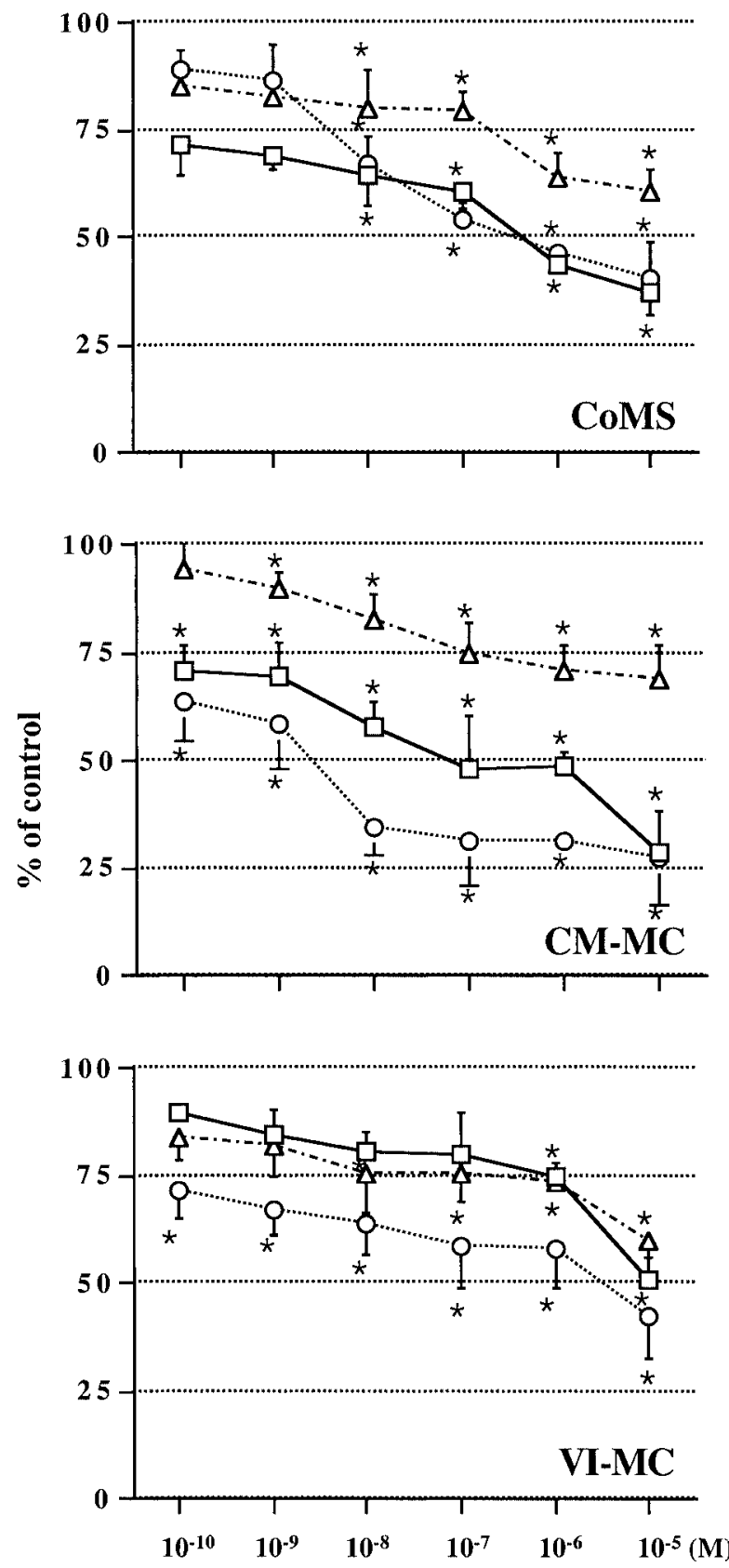

Fig. 1. Effects of retinoids on three canine MCT cell lines. Dose response growth inhibition was observed by ATRA (square), 9cRA (circle) and Am80 (triangle). The percentage of viable cell numbers of the treated groups was compared to that of the control $(100 \%)$. The results shown are from 1 representative experiment of 3 conducted. Data are expressed as mean \pm SD. *: Significantly different from control cells $(P<0.05)$.

cells show a uniform reduction in DNA staining ability with PI, which is indicated by the appearance of a sub G1 peak on the DNA histogram. As shown in Table 2, percentages of ATRA-treated and intact CM-MC cells in sub G1-phase
Table 1. IC50 Values $\left(1 \times 10^{-5} \mathrm{M}\right)$ of each retinoids on MCT cell lines

\begin{tabular}{lccc}
\hline & \multicolumn{3}{c}{ Retinoids, IC50 $(\mu \mathrm{M})$} \\
\cline { 2 - 4 } Cell Line & ATRA & 9cRA & Am80 \\
\hline CoMS & 4 & 0.63 & $>10^{\mathrm{a}}$ \\
VI-MC & $>10^{\mathrm{a})}$ & 3.3 & $>10^{\mathrm{a})}$ \\
CM-MC & 0.097 & 0.00212 & $>10^{\mathrm{a}}$ \\
\hline
\end{tabular}

a) $>10$ indicates that the growth inhibition rate was less than $50 \%$ even at the highest dose, $1 \times 10^{-5} \mathrm{M}$.

Table 2. Distribution of cells on cell cycle arrest and apoptosis in $3 \mathrm{MCT}$ cell lines

\begin{tabular}{lcccc}
\hline Cell Line & \% sub G1 & \% G1/G0 & \% S & \% G2/M \\
\hline CoMS C & 5.77 & 65.35 & 10.29 & 18.59 \\
CoMS A & 21.86 & 60.05 & 5.78 & 10.74 \\
VI-MC C & 7.26 & 66.12 & 12.01 & 14.63 \\
VI-MC A & 15.65 & 59.67 & 11.65 & 13.13 \\
CM-MC C & 11.13 & 64.89 & 10.9 & 12.99 \\
CM-MC A & 32.47 & 51.38 & 7.04 & 8.57 \\
\hline
\end{tabular}

The percentages of cells present in sub G1, G0/G1, S and G2/M phases are shown.

The results shown are from 1 representative experiment of 3 conducted.

C: control cells, A: $1 \times 10^{-5} \mathrm{M}$ ATRA-treated cells.

were $32.5 \%$ and $11.1 \%$, respectively, indicating the induction of apoptosis by retinoids. In addition, percentage of Sphase cells decreased from $10.9 \%$ to $7.0 \%$. A decrease in the S-phase population, the DNA synthetic phase, indicates cell-cycle arrest. Although CM-MC cells showed the highest sensitivity to retinoids, less potent but similar result was obtained in both CoMS and VI-MC cells.

Detection of the activation of caspases: To analyze the signaling pathway of retinoid-induced apoptosis, immunoblotting of pro- and activated caspase- 3 was performed after treatment of ATRA. The presence of proteolytic degradation bands (active caspase-3) was observed when CM-MC cells were treated with ATRA (Fig. 2). The expression of these pro- and active caspase- 3 correlated to those detected in MDCK cells, indicating that these antibodies used in this study are cross reactive to these in dogs (data not shown). We confirmed the involvement of caspase in ATRAinduced apoptosis by using ZVAD-FMK, and measuring cell cycle distribution. As shown in Table 3, the proportion of sub G1-phase cells in ATRA-treated CM-MC cells were $31.8 \%$, whereas addition of ZVAD-FMK resulted in decrease of sub G1-phase down to $10.3 \%$. ZVAD-FMK also increased the proportion of S-phase cells from $7.1 \%$ to $9.1 \%$.

Expression of RARs and RXRs: Figure 3 shows the immunoblotting of RARs and RXRs. Three MCT cell lines expressed all the subtypes of RAR and RXR. The data presented here showed that, although there was an apparent difference in sensitivity to retinoids, all the subtypes of RARs and RXRs were detected at the similar level in 3 MCT cell lines. 


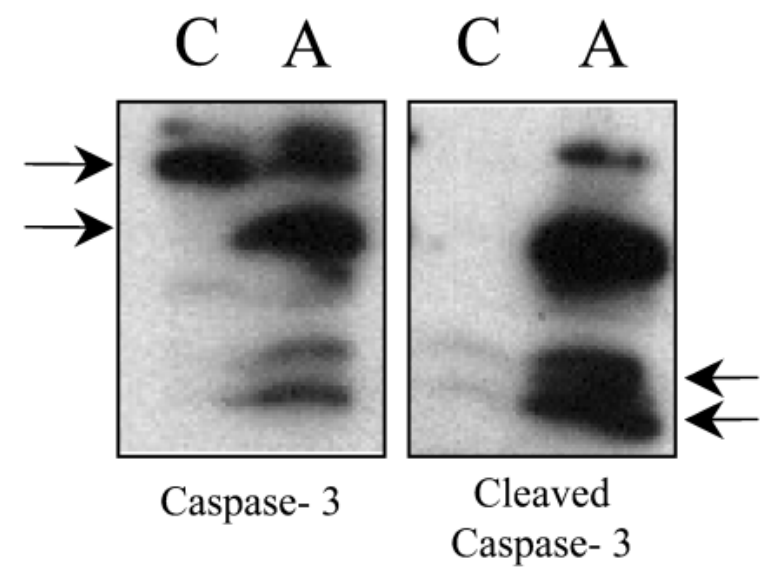

Fig. 2. Induction of caspase-3 activation by retinoids. Western blotting of pro-caspase- 3 antibody (left panel) and active caspase-3 antibody (right panel) in the ATRA-treated (A) and untreated (C) CM-MC cells. Active caspase-3 was detected when cells were treated with ATRA for three days. Antibody for caspase- 3 detects two bands at molecular mass of approximately $35 \mathrm{kDa}$ and $25 \mathrm{kDa}$, while antibody for active caspase- 3 detects band at $19 \mathrm{kDa}$ and $17 \mathrm{kDa}$.

Table 3. Distribution of cells on cell cycle arrest and apoptosis of CM-MC cells after treatment of ATRA $\left(1 \times 10^{-5} \mathrm{M}\right)$ and ZVADFMK $\left(5 \times 10^{-5} \mathrm{M}\right)$

\begin{tabular}{lcccc}
\hline & $\%$ sub G1 & $\% \mathrm{G} 1 / \mathrm{G} 0$ & $\% \mathrm{~S}$ & $\% \mathrm{G} 2 / \mathrm{M}$ \\
\hline Control & 18.88 & 60.83 & 10.2 & 10.39 \\
ATRA & 31.84 & 53.29 & 7.05 & 8.09 \\
ATRA+ZVAD-FMK & 10.32 & 68.4 & 9.11 & 12.29 \\
ZVAD-FMK & 5.74 & 70.02 & 12.26 & 12.24 \\
\hline
\end{tabular}

The percentages of cells present in sub $\mathrm{G} 1, \mathrm{G} 0 / \mathrm{G} 1, \mathrm{~S}$ and $\mathrm{G} 2 / \mathrm{M}$ phases are shown.

The results shown are from 1 representative experiment of 3 conducted.

\section{DISCUSSION}

Retinoids, naturally occurring and synthetic analogues of vitamin A, exhibit a host of interesting effects on the growth and differentiation of normal, preneoplastic and neoplastic cells in vivo and in vitro. In this study, we investigated the antitumor effects of three kinds of retinoids on canine MCT cells in vitro. The data presented in this paper showed that retinoids induced growth inhibition in all three MCT cell lines, with CM-MC showing the highest sensitivity. In addition to the growth inhibition effect, retinoids also induced apoptosis and cell cycle arrest in all the three MCT cells and the ATRA-induced apoptosis was shown to be caspase-dependent. The growth inhibition study shows that the effect of 9cRA was more potent than ATRA in the inhibition of cell growth. Activation of RARs or RXRs requires the dimerization of these receptors. While RARs may only dimerize with RXRs, RXRs can homodimerize as well as dimerize with other nuclear receptors. Thus activation of RXRs can result in the signaling among numerous path- ways. This can be the reason why 9cRA showed more potent growth inhibition compared to ATRA.

Caspases, a family of cystein proteases, play a critical role in the execution of apoptosis. They are activated by proteolytic cleavage from inactive pro-caspases. A member of this family, caspase-3, has been identified as being a key mediator of apoptosis of mammalian cells [24]. In this study, the presence of proteolytic degradation bands resulting from the activation of caspase- 3 was observed. This was confirmed by using a pan-caspase inhibitor, ZVAD-FMK. By adding ZVAD-FMK, ATRA-induced apoptosis was decreased down to $10.3 \%$, even lower than that of the control cells. These results indicate that retinoids induce caspase-dependent apoptosis in MCT cells, and this retinoid-induced apoptosis is partially responsible for growth inhibition of MCT cells by retinoids.

Mast cells are derived from immature hematopoetic cells [10]. Under physiologic conditions, circulating mast cell progenitors reach diverse tissues, where they undergo proliferation and maturation. Uncontrolled proliferation and the accumulation of mast cells occurs in MCTs, whereas the normal process of proliferation and differentiation of mast cells are under the control of cytokines, particularly stem cell factor (SCF), also termed as a Kit ligand [8]. Several years ago, point mutations in c-kit that lead to constitutive activation of Kit in the absence of ligand binding were identified in three malignant mast cell lines (human HMC-1, RBL and mouse P815) $[3,25,26]$. This provides an indication that dysregulation of Kit may promote uncontrolled growth of survival of mast cells. It has been also shown that some malignant canine MCTs express c-kit mutations [14, 15]. Most of these mutations lead to the constitutive phosphorylation of Kit in the absence of ligand binding, resulting in unregulated activation of Kit with subsequent MCT formation. It has recently been reported that ATRA negatively regulates the SCF-dependent differentiation of human mast cells in vitro, and thus results in the decrease of mast cells when ATRA is added to the mast cell progenitor cells [12]. Although the mechanisms by which retinoids act on MCT cells are still unknown, the role retinoids play in regulating the constitutive activation of Kit may be partially responsible for the growth inhibitory effect of retinoids on canine MCT cells.

It is well established that the cellular responses to retinoids are mediated mainly through the regulation of two families of transcription factors, RARs and RXRs [4, 13, 16, 20]. In this study, we have detected all the subtypes of RARs and RXRs in three MCT cell lines. Interestingly, the susceptibility of these MCT cells to retinoids was considerably different. One of the purposes of this study was to determine the correlations between the susceptibility to retinoids and the expressions of RARs and RXRs. Since there was no difference in receptor expression between the cell lines, we could not prove the correlation between the expression of receptors and the reaction of tumor cells in this study. The same results were also obtained in the previous study using canine osteosarcoma cells in our laboratory 
A
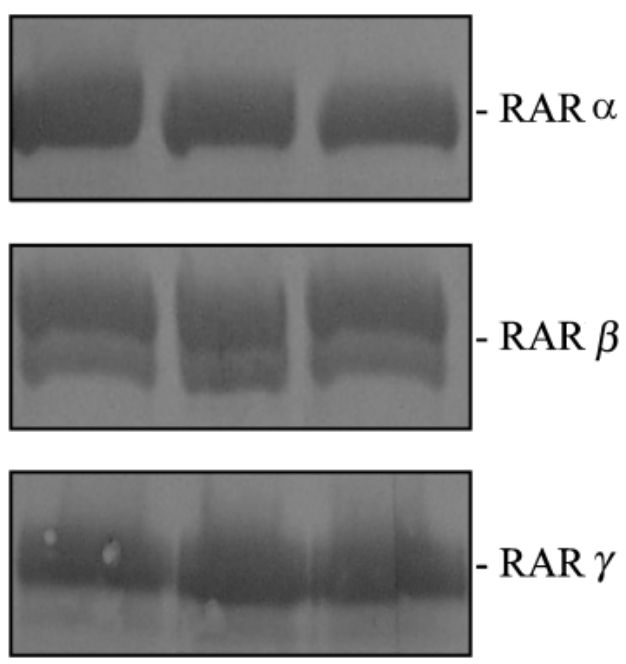

$\mathbf{A}$
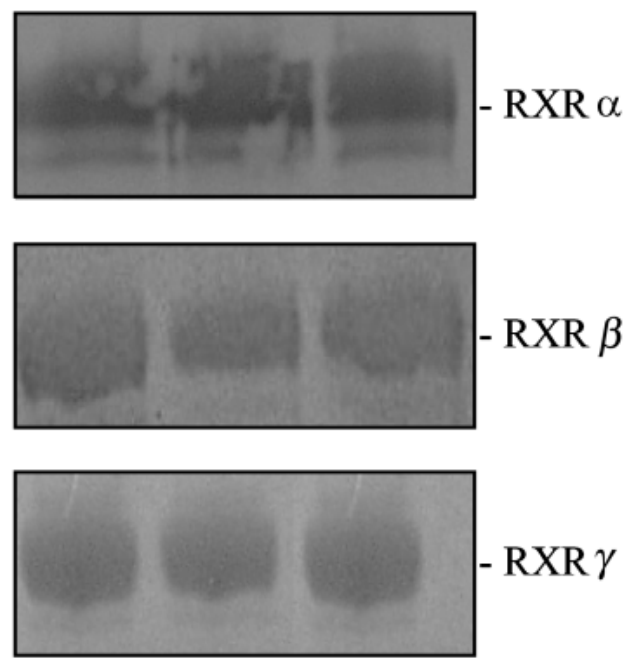

Fig. 3. Western blotting of RARs and RXRs in 3 MCT cell lines. All the subtypes of RARs $\alpha, \beta$ and $\gamma$ and RXRs were detected in 3 MCT cell lines (A, CoMS; B, VI-MC; C, CM-MC). The results shown are from 1 representative experiment of 3 conducted.

[7], but the difference in sensitivity to retinoids has not been clarified yet.

This study is not sufficiently conducted to determine the role of each receptor on the effect of retinoids, but the results obtained here indicate that the receptor responsible for the antiproliferative effect of retinoids on canine MCT cells is not equal to those responsible for the effect on human mast cells. In human mast cell HMC-1, the RAR alpha antagonist showed the equivalent potency to ATRA in the inhibition of mast cell growth, concluding that RAR alpha appears to be the major endogenous RAR subtype for the retinoid-dependent regulation of mast cell proliferation [12]. Am80 is a synthetic retinoid that exhibits RAR alpha-selectivity with some RAR beta-binding ability. Although it has been reported that the RAR alpha-binding affinity of Am80 is higher than that of ATRA [27], its inhibitory effect on cell growth observed in this study was lower compared to ATRA. RAR alpha does not seem to be the major RAR subtype for the regulation of cell growth in MCT cells.

The serum ATRA concentration level of APL patients treated with ATRA is about $10 \mathrm{nM}$. In this study, two of the three MCT cell lines showed significant growth inhibition at this dose. Furthermore, these MCT cell lines were isolated from different primary sites, the skin, gut and oral cavity. $\mathrm{CM}-\mathrm{MC}$, isolated from cutaneous MCT, showed the highest susceptibility to retinoids. Although further investigations are needed, this may indicate that cutaneous MCT has high sensitivity to retinoids.

Canine MCTs are often difficult to control by local treatment, and these tumors are resistant to chemotherapy as well. If retinoids inhibit growth of MCT cells in vivo, as shown in this study in vitro, it is hopeful that the prognosis of MCTs could be improved.

\section{REFERENCES}

1. Allegretto, E.A., McClurg, M.R., Lazarchik, S.B., Clemm, D.L., Kerner, S.A., Elgort, M.G., Boehm, M.F., White, S.K., Pike, J.W. and Heyman, R.A. 1993. Transactivation properties of retinoic acid and retinoid $\mathrm{X}$ receptors in mammalian cells and yeast. Correlation with hormone binding and effects of metabolism. J. Biol .Chem. 268: 26625-26633.

2. Bradford, M.M. 1976. A rapid and sensitive method for the quantitation of microgram quantities of protein utilizing the principle of protein-dye binding. Anal. Biochem. 72: 248-254.

3. Furitsu, T., Tsujimura, T., Tono, T., Ikeda, H., Kitayama, H., Koshimizu, U., Sugahara, H., Butterfield, J.H., Ashman, L.K., Kanayama, Y., Matsuzawa Y., Kitamura, Y. and Kanakura, Y. 1993. Identification of mutations in the coding sequence of the proto-oncogene c-kit in a human mast cell leukemia cell line causing ligand-independent activation of c-kit product. J. Clin. Invest. 92: 1736-1744.

4. Giguere, V., Ong, E.S., Segui, P. and Evans, R.M. 1987. Identification of a receptor for the morphogen retinoic acid. Nature 330: 624-629.

5. Hashimoto, Y., Petkovich, M., Gaub, M.P., Kagechika, H., Shudo, K. and Chambon, P. 1989. The retinoic acid receptors alpha and beta are expressed in the human promyelocytic leukemia cell line HL-60. Mol. Endocrinol. 3: 1046-1052.

6. Hong, S.H., Kadosawa, T., Nozaki, K., Mochizuki, M., Matsunaga, S., Nishimura, R. and Sasaki, N. 2000. In vitro retinoidinduced growth inhibition and morphologic differentiation of canine osteosarcoma cells. Am. J. Vet. Res. 61: 69-73.

7. Hong, S.H., Ohashi, E., Kadosawa, T., Mochizuki, M., Matsunaga, S., Nishimura, R. and Sasaki, N. 2000. Retinoid receptors and the induction of apoptosis in canine osteosarcoma cells. $J$. Vet. Med. Sci. 62: 469-472. 
8. Irani, A.M., Nilsson, G., Miettinen, U., Craig, S.S., Ashman, L.K., Ishizaka, T., Zsebo, K.M. and Schwartz, L.B. 1992. Recombinant human stem cell factor stimulates differentiation of mast cells from dispersed human fetal liver cells. Blood 80: 3009-3021.

9. Ishiguro, T., Kadosawa, T., Mori, K., Takagi, S., Okumura, M. and Fujinaga, T. 2001. Establishment and characterization of a new canine mast cell tumor cell line. J. Vet. Med. Sci. 63: 1031-1034.

10. Ishizaka, T., Mitsui, H., Yanagida, M., Miura, T. and Dvorak, A.M. 1993. Development of human mast cells from their progenitors. Curr. Opin. Immunol. 5: 937-943.

11. Kastner, P., Mark, M. and Chambon, P. 1995. Nonsteroid nuclear receptors: what are genetic studies telling us about their role in real life? Cell 83: 859-869.

12. Kinoshita, T., Koike, K., Mwamtemi, H.H., Ito, S., Ishida, S., Nakazawa, Y., Kurokawa, Y., Sakashita, K., Higuchi, T., Takeuchi, K., Sawai, N., Shiohara, M., Kamijo, T., Kawa, S., Yamashita, T. and Komiyama, A. 2000. Retinoic acid is a negative regulator for the differentiation of cord blood-derived human mast cell progenitors. Blood 95: 2821-2828.

13. Lehmann, J.M., Jong, L., Fanjul, A., Cameron, J.F., Lu, X.P., Haefner, P., Dawson, M.I. and Pfahl, M. 1992. Retinoids selective for retinoid X receptor response pathways. Science 258: 1944-1946.

14. London, C.A., Galli, S.J., Yuuki, T., Hu, Z.Q., Helfand, S.C. and Geissler, E.N. 1999. Spontaneous canine mast cell tumors express tandem duplications in the proto-oncogene c-kit. Exp. Hematol. 27: 689-697.

15. Ma, Y., Longley, B.J., Wang, X., Blount, J.L., Langley, K. and Caughey, G.H. 1999. Clustering of activating mutations in cKIT's juxtamembrane coding region in canine mast cell neoplasms. J. Invest. Dermatol. 112: 165-170.

16. Mangelsdorf, D.J., Ong, E.S., Dyck, J.A. and Evans, R.M. 1990. Nuclear receptor that identifies a novel retinoic acid response pathway. Nature 345: 224-229.

17. Marks, S.L., Song, M.D., Stannard, A.A. and Power, H.T. 1992. Clinical evaluation of etretinate for the treatment of canine solar-induced squamous cell carcinoma and preneoplastic lesions. J. Am. Acad. Dermatol. 27: 11-16.

18. Ohashi, E., Hong, S.H., Takahashi, T., Nakagawa, T., Mochizuki, M., Nishimura, R. and Sasaki, N. 2001. Effect of retinoids on growth inhibition of two canine melanoma cell lines. $J$. Vet. Med. Sci. 63: 83-86.

19. Patnaik, A.K., Ehler, W.J. and McEwen, E.G. 1984. Canine cutaneous mast cell tumor: morphologic grading and survival time in 83 dogs. Vet. Pathol. 21: 469-474.

20. Petkovich, M., Brand, N.J., Krust, A. and Chambon, P. 1987. A human retinoic acid receptor which belongs to the family of nuclear receptors. Nature 330: 444-450.

21. Takahashi, T., Kitani, S., Nagase, M., Mochizuki, M., Nishimura, R., Morita, Y. and Sasaki, N. 2001. IgG-mediated histamine release from canine mastocytoma-derived cells. Int. Arch. Allergy Immunol. 125: 228-235.

22. Tallman, M.S., Andersen, J.W., Schiffer, C.A., Appelbaum, F.R., Feusner, J.H., Ogden, A., Shepherd, L., Willman, C., Bloomfield, C.D., Rowe, J.M. and Wiernik, P.H. 1997. Alltrans-retinoic acid in acute promyelocytic leukemia. New Engl. J. Med. 337: 1021-1028.

23. Thamm, D.H., Mauldin, E.A. and Vail, D.M. 1999. Prednisone and vinblastine chemotherapy for canine mast cell tumor--41 Cases (1992-1997) J. Vet. Intern. Med. 13: 491-497.

24. Thornberry, N.A. and Lazebnik, Y. 1998. Caspases: enemies within. Science 281: 1312-1316.

25. Tsujimura, T., Furitsu, T., Morimoto, M., Kanayama, Y., Nomura, S., Matsuzawa, Y., Kitamura, Y. and Kanakura, Y. 1995. Substitution of an aspartic acid results in constitutive activation of c-kit receptor tyrosine kinase in a rat tumor mast cell line RBL-2H3. Int. Arch. Allergy Immunol. 106: 377-385.

26. Tsujimura, T., Furitsu, T., Morimoto, M., Isozaki, K., Nomura, S., Matsuzawa, Y., Kitamura, Y. and Kanakura, Y. 1994. Ligand-independent activation of c-kit receptor tyrosine kinase in a murine mastocytoma cell line P-815 generated by a point mutation. Blood 83: 2619-2626.

27. Umemiya, H., Fukasawa, H., Ebisawa, M., Eyrolles, L., Kawachi, E., Eisenmann, G., Gronemeyer, H., Hashimoto, Y., Shudo, K. and Kagechika, H. 1997. Regulation of retinoidal actions by diazepinylbenzoic acids. Retinoid synergists which activate the RXR-RAR heterodimers. J. Med. Chem. 40: 42224234.

28. Vail, D.M. 2001. Mast cell tumors. pp. 261-282. In: Small Animal Clinical Oncology, 3rd ed. (McEwen E.G. and Withrow S.J., eds), W. B. Saunders, Philadelphia.

29. White, S.D., Rosychuk, R.A., Scott, K.V., Trettien, A.L., Jonas, L. and Denerolle, P. 1993. Use of isotretinoin and etretinate for the treatment of benign cutaneous neoplasia and cutaneous lymphoma in dogs. J. Am. Vet. Med. Assoc. 202: $387-$ 391.

30. White, S.D., Rosychuk, R.A., Scott, K.V., Hargis, A.M., Jonas, L. and Trettien, A. 1995. Sebaceous adenitis in dogs and results of treatment with isotretinoin and etretinate: 30 cases (1990 1994). J. Am. Vet. Med. Assoc. 207: 197-200. 